\title{
Water barrier properties of carboxymethyl cellulose/halloysite nanotubes nanocomposite to be used in food packaging applications
}

\author{
S.N. Wijesooriya ${ }^{1}$ and N. Adassooriya ${ }^{1,2^{*}}$ \\ ${ }^{1}$ Department of Food Science and Technology, Faculty of Livestock, Fisheries \& Nutrition, Wayamba \\ University of Sri Lanka, Gonawila (NWP), Sri Lanka \\ ${ }^{2}$ Department of Chemical and Process Engineering, Faculty of engineering, University of Peradeniya, \\ Peradeniya Sri Lanka
}

Date Received: 23-11-2021 Date Accepted: 17-12-2021

\begin{abstract}
In this research, novel carboxymethyl cellulose (CMC) based nanocomposite film containing $5 \%$ wt of halloysite nanotubes (HNT) was fabricated via solvent casting method as a potential biodegradable packaging material. The performances of the nanocomposite packaging material was investigated by assessing the moisture content, moisture uptake, water solubility, water vapor barrier properties and opacity. The incorporation of 5\%wt HNT into the film remarkably reduced the moisture uptake by $\sim 28.01 \%$ at $97 \% \mathrm{RH}$ and $31.08 \%$ at $40 \% \mathrm{RH}$. Water permeability value of CMC/HNT film showed as $7.08 \pm 0.26 \times 10^{-11} \mathrm{gm} / \mathrm{m}^{2} \mathrm{Pas}$ at freezing, $3.37 \pm 0.33 \times 10^{-11} \mathrm{gm} / \mathrm{m}^{2} \mathrm{Pas}$ at refrigeration and $1.14 \pm 0.00 \times 10^{-11} \mathrm{gm} / \mathrm{m}^{2}$ Pas at ambient environmental conditions respectively. Subsequent to the thermal annealing process, the water vapor permeation ability was drastically declined in the HNT added nanocomposite films at all three different conditions (freezing, refrigeration and ambient) due to enhancing the crystalline structure. Furthermore, the addition of nanofillers into the polymer matrix significantly induced the UV blocking property of the film. These findings disclosed that prepared $\mathrm{CMC} / 5 \% \mathrm{HNT}$ nanocomposite films can be a potential food packaging material.
\end{abstract}

Keywords: barrier properties, carboxy methyl cellulose, halloysite nanotubes

\section{Introduction}

Afterward the origin of food packaging in the $19^{\text {th }}$ century, protection, hygiene, product quality, and convenience have been leading drivers of food technology and packaging innovation (Kloeckner, 2013). Nowadays, significant attention has been devoted to the development of eco-friendly packaging material with sustainable packaging designs. Biopolymers are widely used for the development of biodegradable packaging materials. Among the carbohydrate based biopolymers, carboxymethyl cellulose (CMC) is one of the key biopolymers used in food packaging industry and it is capable of providing good barrier against the oxygen, carbon dioxide and lipid except water vapor (Li et al., 2008). CMC contains hydrophobic polysaccharide backbone and lots of hydrophilic carboxyl groups $(-\mathrm{CH} 2-\mathrm{COOH})$ in its structure. As a result, it possesses amphiphilic characteristics and very much susceptible to moisture.

*Correspondence:nadeeshm@eng.pdn.ac.lk

(c) University of Sri Jayewardenepura 
A quality food packaging material should preferably shield the food confined within it from odors, loss of flavor, chemicals, oxygen transmittance, and water vapor permeability (WVP). Water barrier property is one of the crucial characteristics in food packaging in order to maintain the quality and extend the shelf life of food products because high WVP can lead the microbial spoilage of the food and can adversely affected to the sensory qualities of the foods.

Nevertheless, using biopolymers as it is caused several disadvantages due to their poor mechanical strength, barrier properties and processing abilities. Therefore, nanotechnology has the potential to generate novel food packaging materials with enhanced performances. Applying nanocomposite can improve properties such as mechanical strength, reduce weight, increase heat resistance and improve barrier against oxygen, carbon dioxide, ultraviolet radiation, moisture, and volatiles of food package materials. Nanoparticles (100 nm or less) are incorporated into biopolymers to improve the properties over those of conventional counterparts while preparing the nanocomposite. Nanoscale insertion comprised of nanoclays, carbon nanotubes, nanoscale metals, oxides, and polymeric resins etc. Incorporation of halloysite (HNT) nanoclay into the biopolymer matrix will be a suitable strategy for the improvement of mechanical properties, water vapor and oxygen barrier properties, and thermal stability while preserving biodegradability (Xu, Ren, and Hanna, 2006).

Halloysite-based nanocomposites have gained specific research attention as a potential material for various biological applications such as antibacterial, enzyme immobilization, and controlled drug delivery (Zhang et al., 2016). Such interest can be hugely attributed to their physicochemical properties, tubular structures, high specific surface area, length-to-diameter (L/D) ratio and hydrophobicity. Furthermore, incorporation of HNT into CMC matrix is able to increase the tensile strength at optimum of $10 \mathrm{wt} \%$, elongation and elasticity of a packaging material (Suppiah et al., 2019). In addition, the inclusion of HNT nanofiller enhance the thermal stability of CMC/HNT bionanocomposite films due to thermal protective layer from char formation (Suppiah et al., 2019).

\section{Materials and Methods}

\subsection{Materials}

Anhydrous $\mathrm{CaCl}_{2}$, glycerol, carboxymethyl cellulose (CMC), sodium salt with an average molecular weight of $90 \mathrm{kDa}$ and HNT from Sigma-Aldrich ChemieGmbh (Schnelldorf, Germany).

\subsection{Film preparation}

Fabrication of CMC based films was carried out by the solvent casting method. Exactly $1.00 \mathrm{~g}$ of CMC was added to $50.0 \mathrm{~mL}$ distilled water $\left(95^{\circ} \mathrm{C}\right)$, mixed at $1200 \mathrm{rpm}$ for $1 \mathrm{~h}$. Then, sonicated solution of the HNT was added dropwise into the CMC film solution, mixed for a further $30 \mathrm{~min}$ at $1200 \mathrm{rpm}$ and $95{ }^{\circ} \mathrm{C}$. Next, glycerol $(50 \% \mathrm{w} / \mathrm{w}$ of CMC) was incorporated as the plasticizer, stirred for 15 min without heating. Finally, the solutions were cooled at room temperature, and $27 \mathrm{~g}$ of the film genic solutions were cast onto a petri dish. The films were dried at $50{ }^{\circ} \mathrm{C}$ for $30 \mathrm{~h}$ in an oven. Dried films were peeled and thermally annealed at $60{ }^{\circ} \mathrm{C}$ for 5 minutes. Films were stored at laboratory conditions in polyethylene bags.

\subsection{Film characterization}

\subsubsection{Fourier transform infrared (FT-IR)}

The nature of chemical bonding of the nanocomposite was determined by using a Bruker Vertex 80 FTIR Spectrometer in the range from 600 to $4000 \mathrm{~cm}^{-1}$ Attenuated Total Reflectance (ATR) technique. 


\subsubsection{Powder X-ray diffraction (PXRD)}

PXRDs of all nanocomposites were recoded using a Rigaku UItimia IV X-ray powder diffract meter using $\mathrm{Cu} \mathrm{K} \propto$ radiation $(\lambda=0.154 \mathrm{~mm})$ over a $2 \Theta$ range of $0-80^{\circ}$ with a step size of 0.04 and step time of 1 second.

\subsubsection{Scanning electron microscopy (SEM)}

Surface morphology and distribution of NPs were characterized by using a HITACHI SU6600 SEM. A film was coated with a thin layer of Au prior to the observation. The film was observed under $2.2 \mathrm{k} X$ magnification.

2.3.4 Fourier transform infrared (FT-IR)

The nature of chemical bonding of the nanocomposite was determined by using a Bruker Vertex 80 FTIR Spectrometer in the range from 600 to $4000 \mathrm{~cm}^{-1}$ Attenuated Total Reflectance (ATR) technique.

\subsubsection{Powder X-ray diffraction (PXRD)}

PXRDs of all nanocomposites were recoded using a Rigaku UItimia IV X-ray powder diffract meter using $\mathrm{Cu} \mathrm{K} \alpha$ radiation $(\lambda=0.154 \mathrm{~mm})$ over a $2 \Theta$ range of $0-80^{\circ}$ with a step size of 0.04 and step time of 1 second.

\subsubsection{Scanning electron microscopy (SEM)}

Surface morphology and distribution of NPs were characterized by using a HITACHI SU6600 SEM. A film was coated with a thin layer of Au prior to the observation. The film was observed under $2.2 \mathrm{k} X$ magnification.

\subsection{Statistical analysis}

All the data were analysed by using completely randomized design and analysis of variance (ANOVA) in SPSS 16.0 statistical software and excel. Then data obtained from the pristine CMC film and the CMC/5\%HNT were subjected to Tukey HSD Post Hoc Test to compare the different parameters among the films. Statistical significance was determined at $\mathrm{p}<0.05$ and values were presented as mean \pm standard deviation.

\subsection{Density}

The film density $(\rho$ ) was calculated directly from the film weight and dimensions according to the Equation [1].

$$
\rho_{\mathrm{s}}=\mathrm{m} / \mathrm{Ad}
$$

Where A is the film area $\left(2 \times 2 \mathrm{~cm}^{2}\right), \mathrm{d}$ is the film thickness $(\mathrm{cm}), \mathrm{m}$ is the film dry mass $(\mathrm{g})$ and $\rho_{\mathrm{s}}$ is the dry matter density of the film $\left(\mathrm{g} / \mathrm{cm}^{3}\right)$.

\subsection{Thickness}

Film thickness was measured with a micrometer (JAICO). Measurements were taken at the center of the film and at four positions around the perimeter.

\subsection{Moisture content $(M C)$}

*Correspondence:nadeeshm@eng.pdn.ac.lk

(C) University of Sri Jayewardenepura 
Moisture contents of the film samples were determined by measuring the weight loss of films before and after drying in an oven at $103 \pm 2{ }^{\circ} \mathrm{C}$ until gaining a constant weight. MC was calculated with Equation [2] in triplicate.

$$
\text { Drying MC }(\%)=\left(\mathrm{W}_{1}-\mathrm{W}_{2} / \mathrm{W}_{1}\right) \times 100
$$

Where $\mathrm{W}_{1}$ was the initial weight of the specimen and $\mathrm{W}_{2}$ was the weight of the specimen after oven dried.

\subsection{Water vapor permeability (WVP)}

The WVP was measured gravimetrically according to the ASTME 96-00 method with slight modifications. The Test tubes containing $6 \mathrm{~g}$ anhydrous calcium chloride $(0 \% \mathrm{RH})$ were sealed by films without pinholes or defects and then placed in different conditions such as refrigeration, freezing and ambient environmental conditions. The test tubes with the films were weighted at intervals of 30 min during the first $12 \mathrm{~h}$ and finally after 24,48 and $72 \mathrm{~h}$. When the relationship between the weight gained and time was linear, the slope of the plots was calculated by linear regression. Regression coefficients were greater than 0.99. The WVP was calculated using equation [3].

$$
\mathrm{WVP}=(\text { Slope. } \mathrm{x}) / \mathrm{A} . \mathrm{S}\left(\mathrm{R}_{1}-\mathrm{R}_{2}\right)
$$

Where $A$ is the area of the exposed film surface $\left(\mathrm{m}^{2}\right), \mathrm{S}$ is the saturation vapor pressure at the test temperature $(\mathrm{kPa}), \mathrm{R}_{1}$ is the relative humidity inside the desiccator, $\mathrm{R}_{2}$ is the relative humidity inside the glass cups, and $\mathrm{x}$ is the average film thickness $(\mathrm{mm})$.

\subsection{Moisture uptake}

Moisture uptake of the films was measured by the method of Angles and Dufresne (Angles and Dufresne, 2000) with minor modifications. The square cut of film samples $\left(2 \times 2 \mathrm{~cm}^{2}\right)$ was first conditioned at $0 \% \mathrm{RH}$ using anhydrous calcium chloride for 3 days at room temperature. After weighing, they were conditioned at $29 \pm 1{ }^{\circ} \mathrm{C}$ in a desiccator containing $\mathrm{K}_{2} \mathrm{SO}_{4}$ saturated solution $(97 \% \mathrm{RH})$ and normal ambient environmental conditions. The weight of the samples was recorded every $24 \mathrm{~h}$ until a constant weight was reached. The moisture uptake values of the samples were calculated by Equation [4].

$$
\text { Moisture uptake }=\left(\mathrm{W}_{\mathrm{t}}-\mathrm{W}_{\mathrm{o}} / \mathrm{W}_{\mathrm{o}}\right) \times 100
$$

Where, $\mathrm{W}_{\mathrm{t}}$ and $\mathrm{W}_{0}$ are the weights of the sample after $\mathrm{t}$ time conditioning at different humidities and the initial weight of the sample, respectively.

\subsection{Water solubility (WS)}

Solubility in the water of the nanocomposite was measured by the method of Almasi et al. (2010) with minor modification. Pieces of the film $\left(2 \times 2 \mathrm{~cm}^{2}\right)$ were cut from each film type and were kept in a desiccator containing anhydrous calcium chloride $(0 \% \mathrm{RH})$ till they reached constant weight. Then, the dried films were immersed in beakers containing $50.0 \mathrm{~mL}$ of distilled water at room temperature for $24 \mathrm{~h}$ with periodical gentle manual agitation. After that period, the remaining pieces of films were taken out and dried at $103 \pm 2{ }^{\circ} \mathrm{C}$ until gaining a constant weight (final dry weight). The percentage of the total soluble matter (\% TSM) of the films was calculated using equation [5].

$$
\% \mathrm{TSM}=(\text { initial dry } \mathrm{wt}-\text { final dry wt/initial dry wt }) \times 100
$$

\subsection{Opacity}

The UV-Vis transmission spectra of nanocomposite films were recorded from 400 to $800 \mathrm{~nm}$ using a UV-Vis spectrophotometer model J.P. SELECTA, s.a (Spain). The film specimen with a well-controlled 
thickness was placed in a spectrophotometer test cell directly and the air was used as a reference. The opacity values (AU nm/mm) of the films were calculated by Equation [6] (Taghizadeh et al., 2013).

$$
\text { Opacity }=\text { Abs600/X }
$$

Where Abs600 is the value of absorbance at $600 \mathrm{~nm}(\mathrm{AU} \mathrm{nm})$ and $\mathrm{X}$ represents the film thickness (mm).

\section{Results and Discussion}

\subsection{Film characterization}

\subsubsection{Powder X-ray Diffraction}

Powder X-ray Diffraction (XRD) is a versatile, non-destructive technique used for qualitative and quantitative analysis of a crystalline structure. The PXRD patterns for HNT, pristine CMC film, and 5\% HNT/CMC nanocomposite films are illustrated in figure 1(a). The diffraction peaks at 12.3, 19.8, 24.9, 26.9 and 34.9 indexed the HNT. The pristine CMC film showed a relatively broad diffraction peak with a maximum appearing at nearly $2 \Theta$ value of $20^{\circ}$ indicating a semi crystalline structure. In the PXRD pattern of CMC/HNT films, peaks of HNT could be identified. It was revealed that the diffraction peaks of HNT became gradually clearer with increment of their concentrations. It should be noted that the appearance and growth of crystal regions of added components might demonstrate low compatibility and affinity with a polymer matrix(Oleyaei, Zahedi, et al., 2016).

\subsubsection{FT- IR}

FT-IR analysis was carried out estimate the possible interactions among CMC and HNT. The FTIR spectra of CMC film, HNT and CMC/5\%HNT nanocomposite are manifested in figure 1(b). The FTIR spectrum of pristine CMC film showed a broad absorption peak at 3354-3454 $\mathrm{cm}^{-1}$ which indicated the stretching frequency of the $\mathrm{O}-\mathrm{H}$ group. The intense absorption peak at $1318 \mathrm{~cm}^{-1}$ corresponds to $\mathrm{OH}$ bending vibrations. The absorption peak at $2914 \mathrm{~cm}^{-1}$ was attributed to the stretching vibrations of the C$\mathrm{H}$ bonds. Two strong peaks appeared at 1462 and $1603 \mathrm{~cm}^{-1}$ were owing to the symmetric and asymmetric stretching vibrations of the carboxylate groups (Rosca et al., 2005). The bands at 1172, 1062 and 1025 $\mathrm{cm}^{-1}$ belong to the $\mathrm{C}-\mathrm{O}$ stretching vibrations (C-O-C), which are characteristic of the polysaccharide skeleton(Yu et al., 2009). The FT-IR spectrum of the nanocomposite films showed a slight shifting of peak positions compared to pristine CMC. For instances, C-O and C-H vibrations of CMC have shifted from $1172 \mathrm{~cm}^{-1}$ to $1106 \mathrm{~cm}^{-1}$ and $2914 \mathrm{~cm}^{-1}$ to $2920 \mathrm{~cm}^{-1}$ respectively. The peak shifts confirm the interaction between CMC and HNT.

\subsubsection{Surface morphology}

The surface morphology of the CMC/5\%HNT nanocomposite films was obtained by SEM under $2.2 \mathrm{k}$ X magnification. Figure 1(c) indicated that HNT was uniformly dispersed through the film surface by signifying excellent barrier properties of the nanocomposite. The surface of the neat CMC film was relatively smooth without cracks or holes and air bubbles. Roughness was imposed on the film's surface by nanomaterials especially at a higher level.

*Correspondence:nadeeshm@eng.pdn.ac.lk

(C) University of Sri Jayewardenepura 

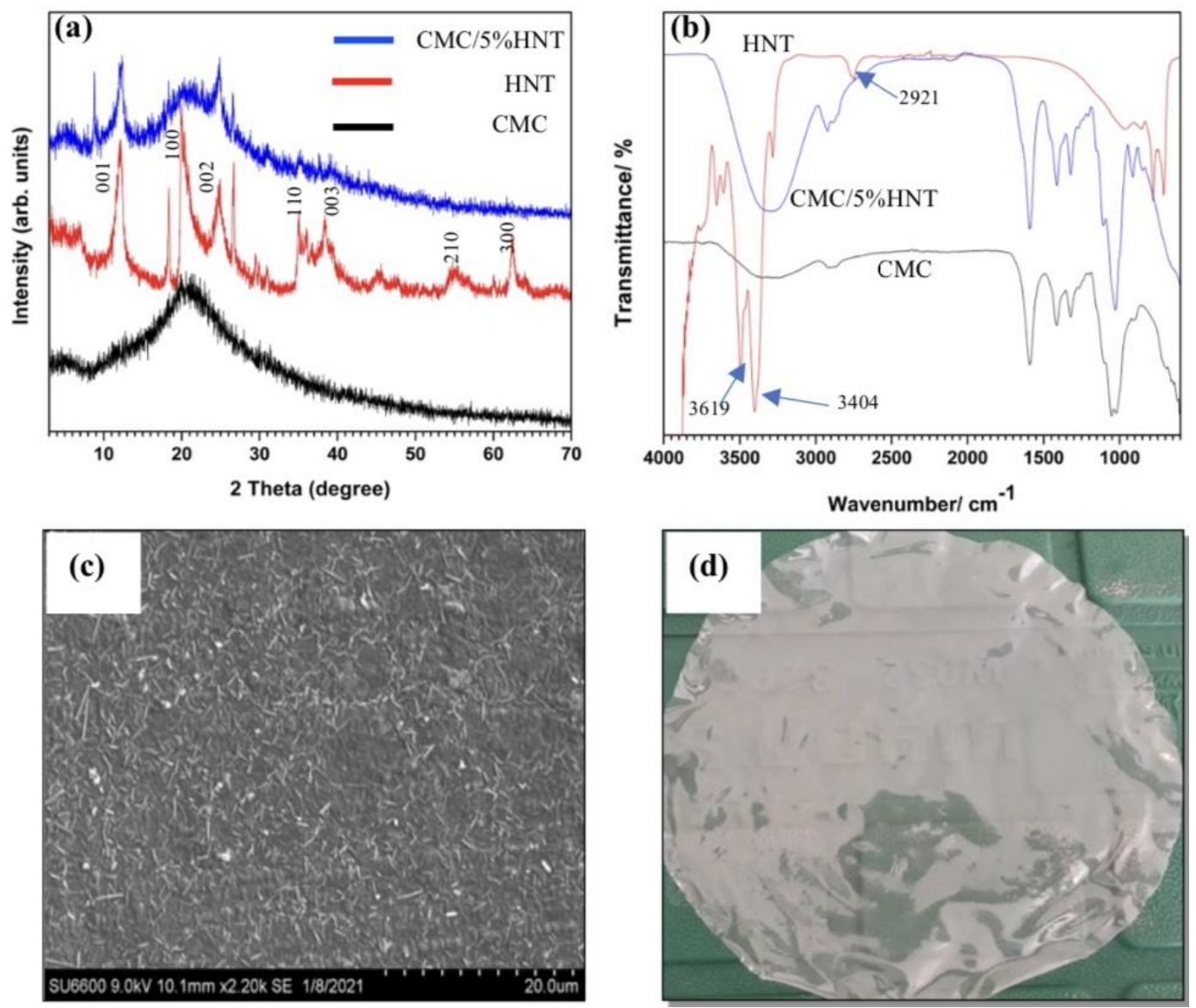

Figure 1- a: PXRD patterns of CMC, HNT and CMC/5\%HNT nanocomposite film.

b: FT-IR spectra of CMC, HNT and CMC/5\%HNT nanocomposite film.

c: Scanning electron microscopy image of CMC/5\%HNTnanocomposite film under $2.2 \mathrm{k}$ magnification.

\subsection{Thickness and density}

The average thickness of the film was $0.11 \mathrm{~mm}$ and it indicated that the inclusion of HNT was not significantly influence the thickness of the film. It is attributed to the fact that the Films thickness depends on different factors, mainly the solid content of the film forming solution at casting. In contrast, the density of the HNT loaded film compared to the pristine CMC film notably increased.

Table 1: Average thickness and density of CMC and CMC/5\%HNT films.

\begin{tabular}{lll}
\hline Film type & Thickness $(\mathbf{m m})$ & Density $\left(\mathbf{g} / \mathbf{c m}^{\mathbf{3}}\right)$ \\
\hline CMC & $0.09 \pm 0.000^{\mathrm{a}}$ & $2.10 \pm 0.02^{\mathrm{a}}$ \\
CMC/5\%HNT & $0.11 \pm 0.005^{\mathrm{a}}$ & $2.54 \pm 0.08^{\mathrm{b}}$ \\
\hline
\end{tabular}

Means with different letters within a column indicate significant differences $(\mathrm{p} \leq 0.05)$. 


\subsection{Moisture content (MC) and moisture uptake}

The moisture content of the CMC/HNT film was not affected by incorporating 5\% HNT. However, the loading of HNT into the films significantly drop the moisture uptake of the nanocomposite at $97 \% \mathrm{RH}$ condition and as well as the ambient environmental conditions. Therefore, a remarkable reduction in moisture uptake ( $28.01 \%$ at $97 \%$ RH and $31.08 \%$ at $40 \% \mathrm{RH})$ was obtained by adding $5 \%$ wt HNT. This may be attributed to the fact that the establishment of strong hydrogen bonds between hydroxyl groups of $\mathrm{CMC}$ and HNT might lessen the available $\mathrm{OH}$ groups of biopolymer matrix which could reduce the nanocomposite moisture uptake (Almasi, Ghanbarzadeh and Entezami, 2010, Zahedi, Fathi-Achachlouei and Yousefi, 2018).

\subsection{Water solubility (WS)}

As the polymer matrix is comprised of CMC, both pristine CMC film and HNT loaded film were fully dissolved in water within a shorter time period (4-6 h). In order to decrease the water solubility, film samples were thermally annealed as thermal annealing is an additional polymer processing step or post treatment processing step enables the structural changes of amorphous parts into crystalline parts (Pastorek and Kovalcik, 2018). Consequently, thermally annealed films took a considerable amount of time to fully dissolve. As reported by the results of pristine CMC film showed the least water solubility compared to the HNT added nanocomposite film. Similar study conducted by Naidu et al. (2020), found that the solubilities of the Xylan/Alginate/3\% HNT and Xylan/Alginate/5\% HNT nanocomposites are 96.33\% and $95.74 \%$ respectively. Therefore, water solubility of the film is directly governed by the characteristic of the polymer matrix and the incorporated nanofiller.

Table 2: Water related properties of $\mathrm{CMC}$ and $\mathrm{CMC} / 5 \% \mathrm{HNT}$ nanocomposite films.

\begin{tabular}{lllll}
\hline Film sample & Moisture & \multicolumn{2}{c}{ Moisture uptake\% } & Water \\
& Content \% & At 97\% RH & At 40\% RH & solubility\% \\
& & & & \\
& & & & \\
& & & & \\
& & & \\
CMC & $27.4 \pm 0.54^{\mathrm{a}}$ & $387.7 \pm 7.82^{\mathrm{a}}$ & $41.5 \pm 1.47^{\mathrm{a}}$ & $83.2 \pm 1.2$ \\
$\mathrm{CMC} / 5 \% \mathrm{HNT}$ & $28.0 \pm 1.62^{\mathrm{a}}$ & $279.1 \pm 4.52^{\mathrm{b}}$ & $28.6 \pm 1.25^{\mathrm{a}}$ & $85.7 \pm 0.9$ \\
\hline
\end{tabular}

Means with different letters within a column indicate significant differences $(\mathrm{p} \leq 0.05)$.

\subsection{Water vapor permeability (WVP)}

The solubility of water in the polymer is likely to be controlled by the WVP through polymer films. The polarity of the polymer governs the water barrier properties. Therefore, high polar polymers show the least barrier properties due to the high solubility. The quota of hydrogen bonds in the biopolymeric film and the addition of hydrophilic plasticizers are induced the WVP value. Results revealed that by adding $5 \%$ HNT into the CMC polymer matrix exhibit an excellent barrier property against the water vapor at all three conditions compared to the pristine $\mathrm{CMC}$ film and it is reported that water vapor barrier properties increased by $18.92 \%$ at freezing condition, $21.66 \%$ at refrigeration condition and $7.89 \%$ at ambient environmental conditions.

*Correspondence:nadeeshm@eng.pdn.ac.lk

(C) University of Sri Jayewardenepura 
Similarly, the results reported by Naidu et al. (2020), depicted that incorporation of $5 \mathrm{wt} \% \mathrm{HNT}$ into Xylan-Alginate matrix reduced the WVP of the film by $48.98 \%$ at $75 \% \mathrm{RH}$. Moreover, the WVP of bionanocomposite film (poly(vinyl) alcohol /starch / glycerol/HNT) was found to be reduced significantly by $65.26 \%$ with increasing the HNT content from 0 to $5 \mathrm{wt} \%$ at the RH level between $10 \%$ and $70 \% \pm 2 \%$ (Abdullah et al., 2019). In addition, when compared the WVP value of CMC matrix which was reinforced with nanochitosan and nanocellulose, it was revealed that $1 \%$ nanochitosan and $1 \%$ nanocellulose able to decreased the water vapor permeation by $42.3 \%$ and $64.1 \%$ respectively compared to the pristine CMC film (Jannatyha et al., 2020).

Table 3: Water vapor permeability values of $\mathrm{CMC}$ and $\mathrm{CMC} / 5 \% \mathrm{HNT}$ nanocomposite films at different conditions.

Film sample $\quad$ Water vapor permeability $\left(\times 10^{-11} \mathrm{gm} / \mathrm{m}^{2} \mathrm{Pas}\right)$

$\begin{array}{lll}\begin{array}{l}\text { Freezing } \\ \text { conditions }\end{array} & \begin{array}{l}\text { Refrigeration } \\ \text { conditions }\end{array} & \begin{array}{l}\text { Ambient } \\ \text { environment } \\ \text { conditions }\end{array}\end{array}$

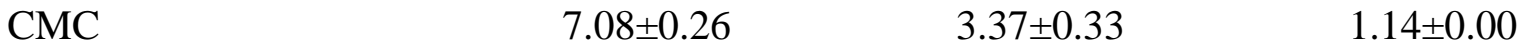

$\begin{array}{llll}\mathrm{CMC} / 5 \% \mathrm{HNT} & 5.74 \pm 1.60 & 2.64 \pm 0.20 & 1.05 \pm 0.21\end{array}$

\subsection{Opacity}

Ultraviolet barriers and transparency are important optical properties for packaging material. UV blocking shielding ability of the film is necessary to prevent photocatalytic reactions and color changes, and high transparency allows consumers to see through the packaged foods (Roy and Rhim, 2020). The pristine CMC film was transparent and colorless. The addition of HNT give rise to a transparent to translucent film by hindering the light passage through the film (Wang and Rhim, 2017).

\section{Conclusion}

The objective of this research was to develop a novel bio nanocomposite as an ecofriendly solution for non-biodegradable packaging materials. HNT was used to enhance the performance of the biopolymer. $\mathrm{CMC} / 5 \% \mathrm{HNT}$ film and pristine CMC film were tested against different parameters. Measurements of the nanocomposite indicated the denser matrix $\left(2.54 \pm 0.08 \mathrm{~g} / \mathrm{cm}^{3}\right.$ at $\left.\mathrm{p} \leq 0.05\right)$, reduced WVP by $18.92 \%$ at freezing condition, $21.66 \%$ at refrigeration condition and $7.89 \%$ at ambient environmental conditions. Moisture uptake ability of the nanocomposite was drastically declined by $28.01 \%$ at $97 \%$ RH and by $31.08 \%$ at the $40 \%$ RH. HNT able to block UV light by hindering the light passing through the nanocomposite film. FT-IR spectroscopy, PXRD and SEM examinations evidenced good interactions between CMC and HNT. In summary, CMC/5\%HNT nanocomposite film exhibited better performance and can be suggested as potential eco-friendly food packaging material. 


\section{Acknowledgment}

SNW and NA thank Instrument Centre, Faculty of Applied Sciences, University of Sri Jayewardenepura and Sri Lanka Institute of Nanotechnology for the support given for materials characterisation.

\section{References}

Abdullah, Z.W., Dong, Y., Han, N. and Liu, S., (2019). Water and gas barrier properties of polyvinyl alcohol (PVA)/starch (ST)/glycerol (GL)/halloysite nanotube (HNT) bionanocomposite films: experimental characterization and modelling approach. Composites Part B: Engineering, 174, p.107033.

Almasi, H., Ghanbarzadeh, B. and Entezami, A. A. (2010). CMC - nanoclay biodegradable films. International Journal of Biological Macromolecules Physicochemical properties of starch, 10.1016

Angles, M.N. and Dufresne, A., 2000. Plasticized starch/tunicin whiskers nanocomposites. 1. Structural analysis. Macromolecules, 33(22), pp.8344-8353.

Jannatyha, N., Shojaee-Aliabadi, S., Moslehishad, M. and Moradi, E., (2020). Comparing mechanical, barrier and antimicrobial properties of nanocellulose/CMC and nanochitosan/CMC composite films. International Journal of Biological Macromolecules, 164, pp.2323-2328.

Kloeckner, B. (2013). Optimal transport and dynamics of expanding circle maps acting on measures. Ergodic Theory and Dynamical Systems, 10.1017/S014338571100109X.

Li, Y., Shoemaker, C.F., Ma, J., Shen, X. and Zhong, F., (2008). Paste viscosity of rice starches of different amylose content and carboxymethylcellulose formed by dry heating and the physical properties of their films. Food Chemistry, 109(3), pp.616-623.

M.T. Taghizadeh, N. Sabouri, B. Ghanbarzadeh, Polyvinyl alcohol: starch: carboxymethyl cellulose containing sodium montmorillonite clay blends; mechanical properties and biodegradation behavior, Springer Plus 2 (1) (2013) 376.

Naidu, D.S. and John, M.J., (2020). Effect of clay nanofillers on the mechanical and water vapor permeability properties of xylan-alginate films. Polymers, 12(10), p.2279.

Oleyaei, S.A., Zahedi, Y., Ghanbarzadeh, B. and Moayedi, A.A., (2016). Modification of physicochemical and thermal properties of starch films by incorporation of $\mathrm{TiO}_{2}$ nanoparticles. International Journal of Biological Macromolecules, 89, 256-264

Pastorek, M. and Kovalcik, A. (2018). Effects of thermal annealing as polymer processing step on poly(lactic acid). Materials and Manufacturing Processes, 10.1080/10426914.2018.1453153.

Rosca, C., Popa, M.I., Lisa, G. and Chitanu, G.C., (2005). Interaction of chitosan with natural or synthetic anionic polyelectrolytes. 1 . The chitosan-carboxymethylcellulose complex. Carbohydrate polymers, 62(1), pp.35-41.

Roy, S. and Rhim, J. W. (2020).Carboxymethyl cellulose-based antioxidant and antimicrobial active packaging film incorporated with curcumin and zinc oxide. International Journal of Biological Macromolecules, 10.1016

Suppiah, K., Teh, P.L., Husseinsyah, S. and Rahman, R., (2019). Properties and characterization of carboxymethyl cellulose/halloysite nanotube bio-nanocomposite films: Effect of sodium dodecyl sulfate. Polymer Bulletin, 76(1), pp.365-386.

*Correspondence:nadeeshm@eng.pdn.ac.lk

(C) University of Sri Jayewardenepura 
Wang, L. and Rhim, J. (2017) .Applied Clay Science Functionalization of halloysite nanotubes for the preparation of carboxymethyl cellulose-based nanocomposite films. Applied Clay Science, 10.1016/j.clay.

Xu, Y., Ren, X. and Hanna, M.A., (2006). Chitosan/clay nanocomposite film preparation and characterization. Journal of applied polymer science, 99(4), pp.1684-1691.

$\mathrm{Yu}$, J. et al. (2009). Preparation and characterization of glycerol plasticized-pea starch/ZnOcarboxymethylcellulose sodium nanocomposites. Bioresource Technology, 10.1016/j.biortech.2008.12.045.

Zahedi, Y., Fathi-Achachlouei, B. and Yousefi, A. R. (2018). Physical and mechanical properties of hybrid montmorillonite/zinc oxide reinforced carboxymethyl cellulose nanocomposites. International Journal of Biological Macromolecules, 10.1016/j.ijbiomac.2017.10.185.

Zhang Y, Long M, Huang P, Yang H, Chang S, Hu Y, Tang A, Mao L (2017). Intercalated 2D nanoclay for emerging drug delivery in cancer therapy. Nano Research, 1;10(8):2633-43. 